\title{
COMPARAÇÃO ENTRE MÉTODOS PADRONIZADOS E NOVAS METODOLOGIAS PARA ESTIMAR O TAMANHO DE GRÃOS EM MATERIAIS METÁLICOS*
}

Diego de Araujo Santana ${ }^{1}$ Geraldo Lúcio de Faria²

\section{Resumo}

O tamanho médio dos grãos é um parâmetro estrutural frequentemente estimado quando se está avaliando, principalmente, as propriedades mecânicas dos materiais metálicos. A American Society for Testing and Materials (ASTM) estabelece, nas normas ASTM E112 e ASTM E1382, metodologias para estimar o tamanho médio dos cristais de maneira manual e semiautomática/automática, respectivamente. $O$ presente trabalho propõe, além de uma nova metodologia semiautomática, duas metodologias automáticas para estimar o tamanhão médio de grão em materiais metálicos policristalinos monofásicos, assim como um parâmetro para avaliar a morfologia dos grãos. O tamanho de grão G ASTM encontrado utilizando os novos procedimentos testados se apresentou muito próximo aos valores obtidos pelos métodos padronizados, que também foram aplicados e usados como referência para avaliação da representatividade das medidas. Desse modo, os métodos propostos se apresentam como uma alternativa viável para estimar o referido parâmetro estrutural dos materiais metálicos.

Palavras-chave: Tamanho médio de grãos; ASTM E112; ASTM E1382.

\section{COMPARATION BETWEEN STANDARDIZED METHODS AND NEW METHODOLOGIES FOR AGRAIN SIZE ESTIMATION IN METALLIC MATERIALS}

\begin{abstract}
The average grain size is a structural parameter frequently estimated when the mechanical properties of metallic materials are evaluated. The American Society for Testing and Materials (ASTM) standardizes at ASTM E112 and ASTM 1382 methods for determining the average size of crystals by using manual and semiautomatic/automatic procedures, respectively. This work proposes besides a new semiautomatic methodology, two automatic methods for determining the average grain size in monophasic polycrystalline metallic materials, as well as a parameter to evaluate grains shape. The G ASTM grain size obtained by using the new procedures were very similar to the obtained values by employing standard methods, which were also applied and used as reference to evaluate the measures representativeness. So the proposed methods have been a viable alternative for estimating the referred structural parameter in metallic materials.
\end{abstract}

Keywords: Average grain size; ASTM E112; ASTM E1382.

1 Engenheiro Metalúrgico, Mestrando em Ciência e Engenharia de Materiais, DEMa, UFSCar, São Carlos, SP, Brasil.

2 Físico. Dr. Professor. Departamento de Engenharia Metalúrgica e de Materiais (DEMET), EM, UFOP, MG, Brasil 


\section{INTRODUÇÃO}

O tamanho médio de grão é um parâmetro estrutural frequentemente estimado quando se está avaliando, principalmente, as propriedades mecânicas dos materiais metálicos, como limite de escoamento, resistência à tração, tenacidade à fratura, dureza, resistência à fluência entre outras [1-5].

Nesse contexto, algum tipo de metodologia que defina o tamanho médio da unidade estrutural de um material policristalino é de grande importância. A American Society for Testing and Materials (ASTM) define nas normas ASTM E112 e ASTM E1382, uma unidade para avaliação do tamanho de grão $(G)$, bem como procedimentos manuais e semiautomáticos/automáticos, respectivamente, para estimar o referido parâmetro [6,7].

O método dos interceptos, que é o método manual mais preciso para um mesmo número de grãos avaliados, consiste em aplicar várias linhas ou circunferências de comprimentos conhecidos sobre a microestrutura de um material. Determina-se o número de grãos interceptados pela geometria utilizada por seu comprimento e, então, utiliza-se esse valor para definir o tamanho médio dos grãos por meio de equações ou tabelas presentes na norma ASTM E112 [6].

A aplicação do procedimento dos interceptos é bastante simples, entretanto é trabalhosa sob o ponto de vista experimental, visto que é necessário realizar a contagem do número de grãos interceptados em cada região avaliada. Ademais, os resultados das avaliações podem variar de um operador para outro devido à diferença de percepção de cada um.

Os métodos semiautomáticos consistem, basicamente, em aplicar as regras dos procedimentos manuais, previstos na norma ASTM E112, utilizando o auxílio de um computador ou uma mesa digitalizadora [7].

A análise de imagem aplicada a metalografia tem se tornado uma ferramenta importante quando se é exigido à avaliação de um grande número de microestruturas em um curto período de tempo, bem como em processos onde são necessários o máximo de repetibilidade e reprodutibilidade das medidas [8,9].

Além dos métodos semiautomáticos, a norma ASTM E1382 estabelece algumas metodologias para determinar o tamanho médio de grão de modo automático. Nesse caso, são utilizadas técnicas de processamento e análise de imagens para encontrar o número de grãos, a área, o perímetro ou outras propriedades dos grãos. A utilização dessas técnicas diminui o tédio associado às medições manuais, assim permitem a obtenção de grande quantidade de dados e uma amostragem mais extensiva, a qual produz uma melhor definição estatística do tamanho de grão comparado aos procedimentos manuais e semiautomáticos [7].

No presente trabalho são propostas novas metodologias para se estimar o tamanho médio dos grãos num material metálico monofásico, assim como é proposto um parâmetro que determina o quão alongado os grãos estão na estrutura avaliada.

\section{MATERIAIS E MÉTODOS}

\subsection{Material}

O material objeto deste estudo consistiu em uma amostra de um aço patinável (USISAC-350), cuja estrutura era basicamente monofásica ferrítica. A composição química da amostra é apresentada na Tabela 1. 
Tabela 1. Composição química do aço USI-SAC-350 (\%em massa).

\begin{tabular}{|c|c|c|c|c|c|c|c|c|c|c|c|c|}
\hline $\mathbf{C}$ & $\mathbf{M n}$ & $\mathbf{P}$ & $\mathbf{S}$ & $\mathbf{S i}$ & $\mathbf{A l}$ & $\mathbf{C u}$ & $\mathbf{M o}$ & $\mathbf{C r}$ & $\mathbf{N i}$ & $\mathbf{V}$ & $\mathbf{T i}$ & $\mathbf{N}$ \\
\hline 0,1 & 0,78 & 0,036 & 0,009 & 1,108 & 0,03 & 0,087 & 0,002 & 0,23 & 0,012 & 0,004 & 0,001 & 0,0044 \\
\hline
\end{tabular}

\subsection{Métodos}

A amostra foi metalograficamente preparada, atacada com Nital $2 \%$ e, então, teve 20 campos aleatoriamente fotografados utilizando-se aumentos de $200 \mathrm{X}$ e $400 \mathrm{X}$ em um microscópio óptico. As imagens adquiridas em ambas às ampliações foram enumeradas de 1 a 20 conforme a ordem em que foram obtidas. A Figura 1 apresenta a microestrutura do primeiro campo avaliado com os aumentos de $200 \mathrm{X} \mathrm{e}$ 400X.
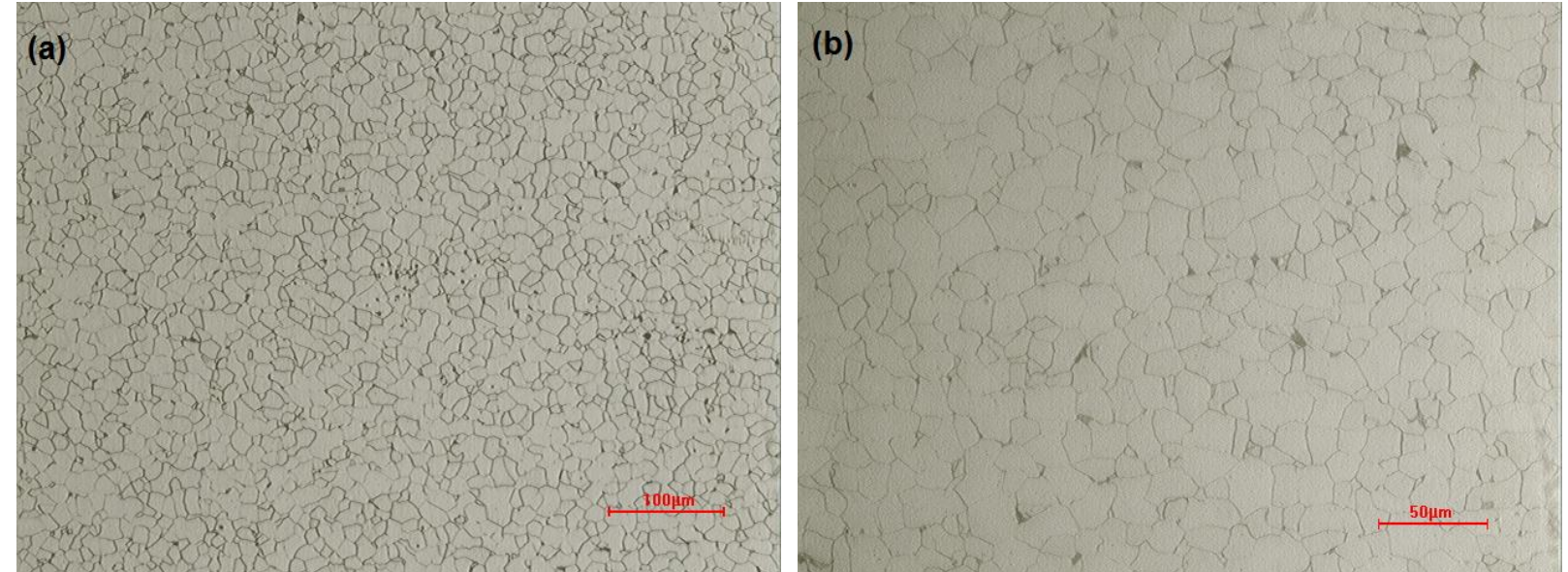

Figura 1. (a)Microestrutura do aço patinável USI-SAC-350 - Nital 2\% MO - 200X; (b) Microestrutura do aço patinável USI-SAC-350 - Nital 2\% MO - 400X.

Utilizando algumas das imagens adquiridas, escolhidas aleatoriamente, o método dos interceptos, padronizado pela ASTM E112, e um procedimento semiautomático proposto foram aplicados.

Posteriormente, o método das áreas individuais, padronizado pela ASTM E1382, bem como dois procedimentos automáticos propostos foram aplicados. O fluxograma apresentado na Figura 2 ilustra as metodologias adotadas na execução deste trabalho.

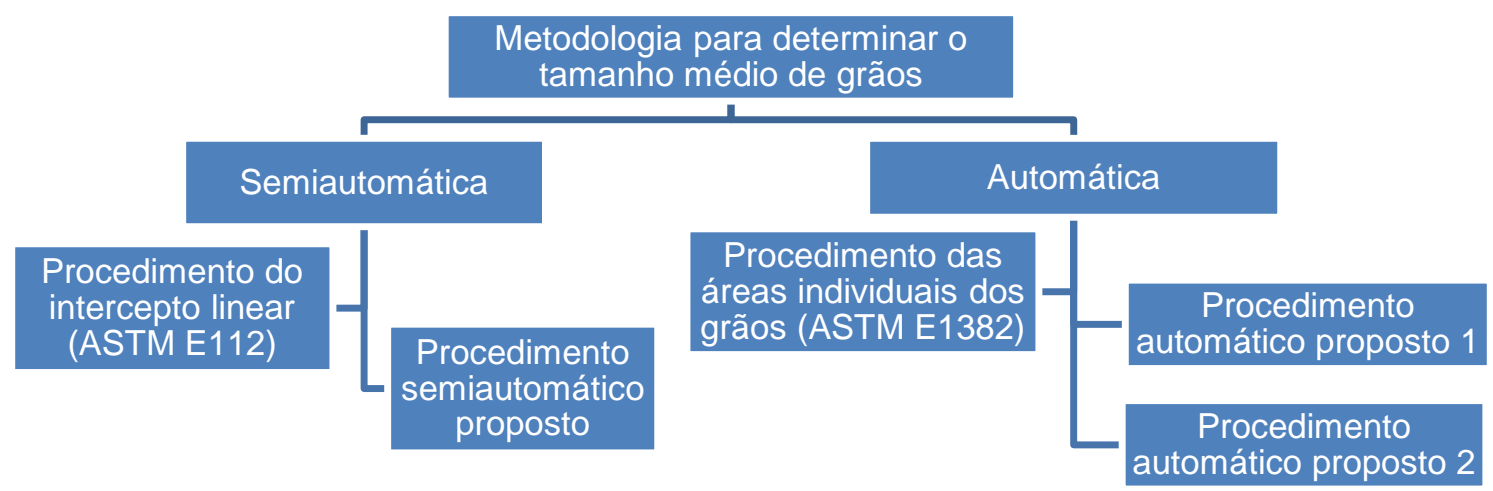

Figura 2. Fluxograma contendo as metodologias utilizadas no presente trabalho.

\subsubsection{Métodos padronizados aplicados}

Com objetivo de se obter um parâmetro de referência para comparar os resultados dos métodos propostos, foi aplicado o procedimento do intercepto linear e o 
procedimento das áreas individuais dos grãos, padronizados pelas normas ASTM E112 e ASTEM 1382, respectivamente.

Método semiautomático do intercepto linear - inicialmente, nove imagens obtidas com aumento de 200X foram carregadas no software UMIAS, o qual é uma ferramenta de captura de imagens, bem como de metalografia quantitativa que oferece alguns recursos para realizar medidas lineares. Na sequência, cinco linhas paralelas aleatórias foram sobrepostas sobre cada imagem e foi realizada a contagem do número de interceptos em cada uma. A precisão relativa foi calculada, como recomendado pela norma ASTM E112, para verificar se campos adicionais deveriam ser considerados. A Figura 3 exemplifica o modelo padrão utilizado para realizar as contagens, na qual cada circulo vermelho indica que um grão foi interceptado pela linha de teste.

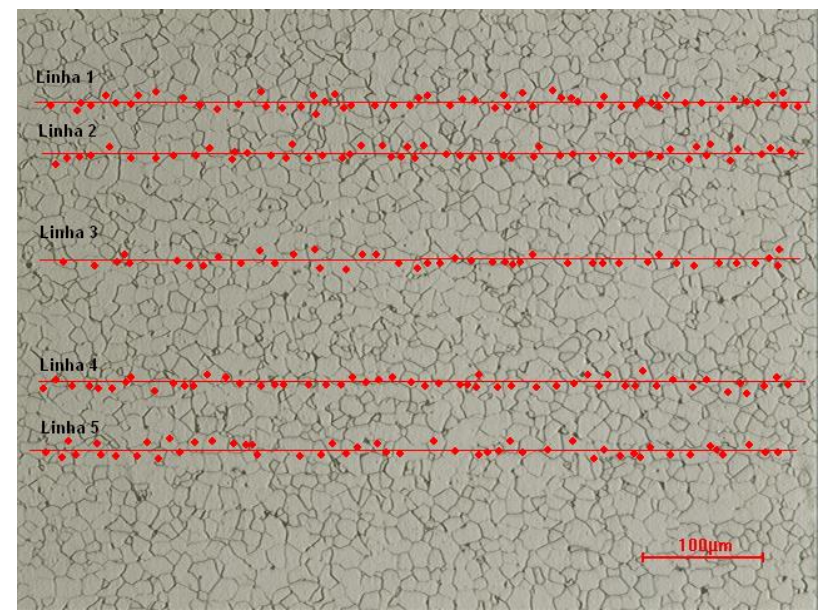

Figura 3. Aplicação do método dos interceptos (ASTM E112) sobre a microestrutura do aço patinável USI-SAC-350 - Nital 2\% MO - 200X.

Método automático das áreas individuais - para a aplicação desse método, primeiramente, foi verificada no software UMIAS a relação pixel-micrometro para as imagens adquiridas com o aumento de 200X. Na sequência, utilizando-se a linguagem de programação open source Python e extendendo suas funcionalidades padrões com as bibliotecas OpenCV e Numpy, as mesmas imagens, utilizadas para determinar o tamanho médio de grão por meio do método semiautomático padronizado, foram segmentadas de modo automático. Devido aos resultados desse processo não serem satisfatórios, visto que os contornos ficaram mal definidos, as fotomicrografias foram segmentadas novamente, mas de modo manual, utilizando o aplicativo Paint do sistema operacional Windows.

Em seguida, um histograma de frequência foi construído para se observar a distribuição dos níveis de cinza na imagem. A partir da análise do referido gráfico foi definido um valor de thresholding e todas as fotomicrografias segmentadas foram binarizadas (o interior dos grãos foi modificado para cor branca e os contornos foram transformados em pretos). Além da utilização dessa técnica, foi desenvolvido um algoritmo para detectar todos os grãos que possuem ao menos um pixel que toca uma das bordas das imagens e esses cristais foram transformados em contornos.

Desenvolveu-se, por fim, um algoritmo em Python para calcular a área média dos grãos individuais, bem como o desvio padrão das medidas, como recomendado pela ASTM E1382. A Figura 4 apresenta os resultados das etapas de segmentação e binarização da Imagem 01. 

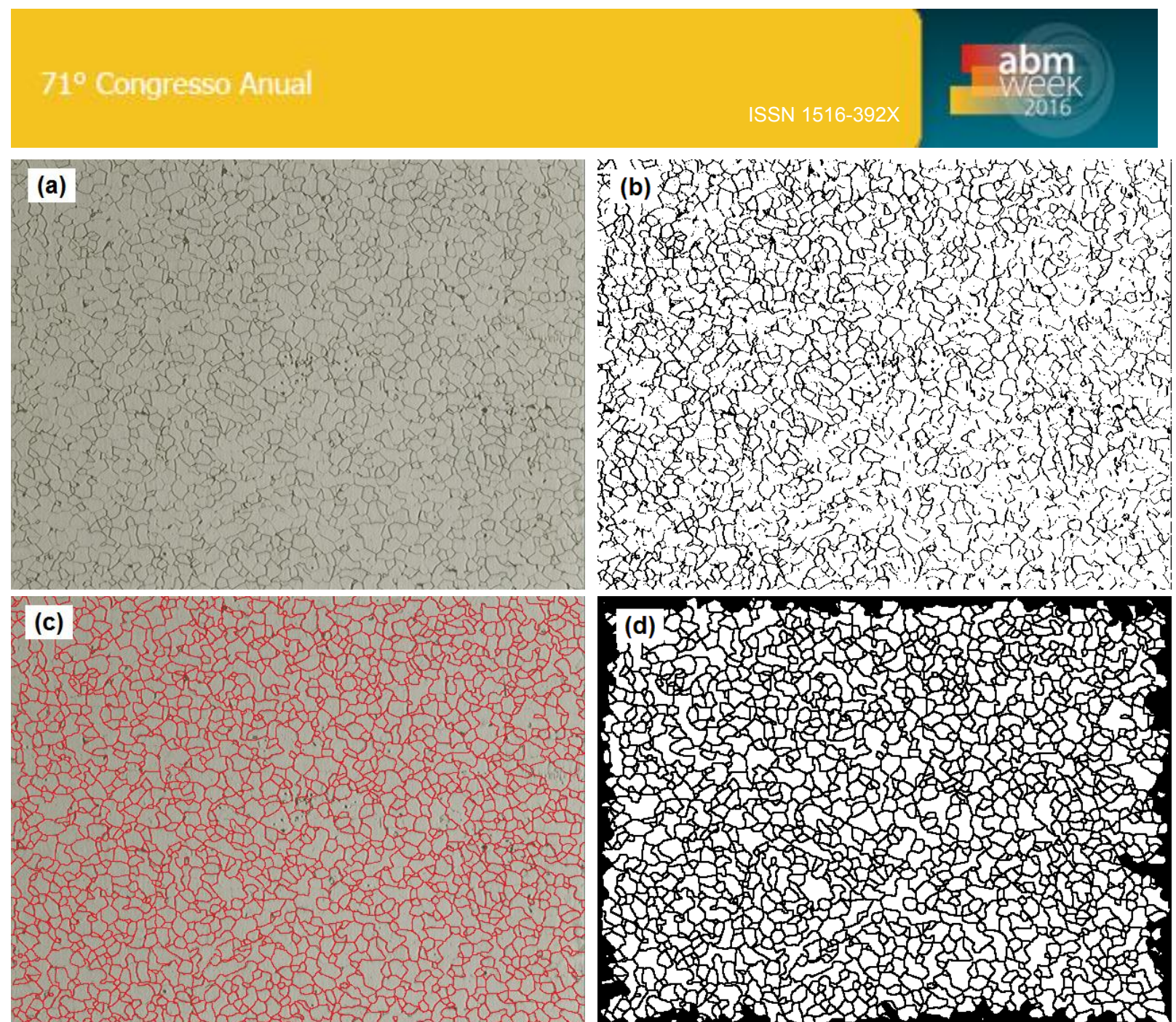

Figura 4. (a) Microestrutura do aço patinável USI-SAC-350 - Nital 2\% MO - 200X; (b) Imagem (a) após segmentação automática; (c) Imagem (a) após segmentação manual utilizando o aplicativo Paint do sistema operacional Windows; (d) Imagem (c) após binarização e conversão dos grãos que tocam as bordas em contornos.

\subsubsection{Métodos propostos}

Foram propostos, além de uma nova metodologia semiautomática, bem como dois procedimentos automáticos para estimar o tamanho médio de grão, um parâmetro que determina a morfologia dos grãos.

Método semiautomático proposto - o procedimento semiautomático proposto consistiu em, aleatoriamente, selecionar nove imagens obtidas com aumento de 400X e medir o comprimento do intercepto linear, na direção horizontal e vertical, de 40 grãos individuais selecionados aleatoriamente em cada uma. As medições foram feitas nas medianas horizontal e vertical dos grãos.

Os grãos foram numerados em ordem crescente da esquerda para direita, de cima para baixo. A Figura 5 exemplifica a metodologia proposta. 

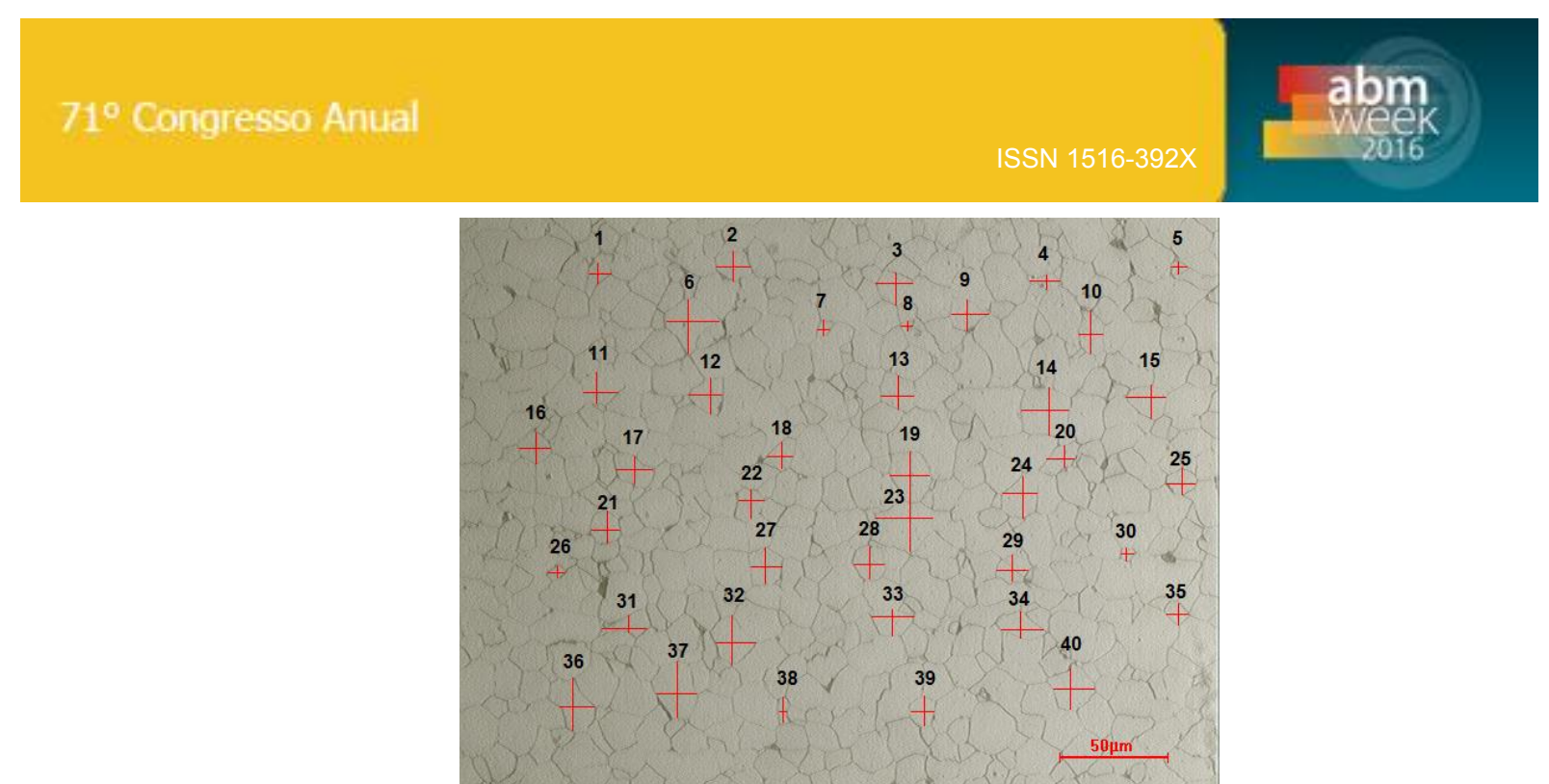

Figura 5. Aplicação do procedimento proposto sobre a microestrutura do aço patinável USI-SAC-350 - Nital $2 \% \mathrm{MO}-400 \mathrm{X}$.

Método automático proposto 1 - o primeiro método automático proposto consistiu em calcular o diâmetro equivalente dos grãos, sendo esse igual ao diâmetro de uma circunferência com a mesma área do grão avaliado. A Equação 1 apresenta o cálculo do diâmetro equivalente.

$$
\text { Diâmetro Equivalente }=\sqrt{\frac{4 \times \text { área dogrão }}{\pi}}
$$

Método automático proposto 2 - o segundo método automático proposto consistiu em calcular a média simples entre os dois principais eixos da elipse que melhor se ajusta a cada grão. A Figura 6 apresenta alguns contornos de grão, indicados pela cor branca, assim como a elipse que melhor se ajusta a cada um com seus principais eixos, indicados pela cor vermelha.

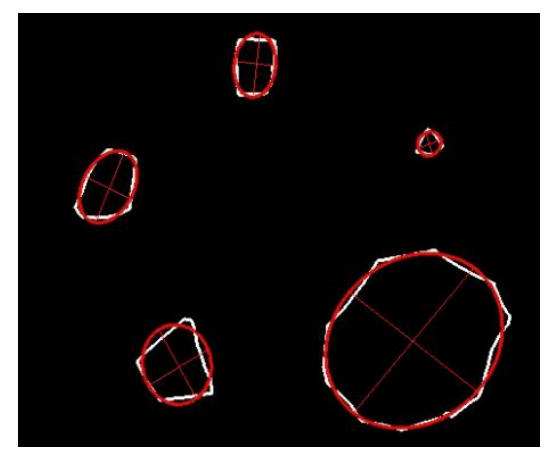

Figura 6. Contornos de grão, indicados pela cor branca, assim como as respectivas elipses que melhor se ajustam a cada um com seus principais eixos (indicados pela cor vermelha).

Parâmetro que determina a morfologia dos grãos - o comprimento dos eixos de cada elipse também foi utilizado para propor um parâmetro que indica o quão alongando os grãos estão na estrutura de um material (referência para anisotropia). O cálculo dessa medida em cada grão é apresentado na Equação 2.

$$
\text { Grau de anisotropia }=\frac{\text { comprimento do maior eixo da elipse }}{\text { comprimento do menor eixo da elipse }}
$$




\section{RESULTADOS E DISCUSSÃO}

\subsection{Métodos Semiautomáticos}

Os valores do intercepto linear médio por imagem, obtidos pelo método semiautomático normatizado aplicado e pelo método proposto, são apresentado na Tabela 2.

Tabela 2. Valores médios por imagem dos interceptos lineares calculados pelas metodologias semiautomáticas normatizada e proposta.

\begin{tabular}{cccc}
\multicolumn{2}{c}{ Método Semiautomático Normatizado } & \multicolumn{2}{c}{ Método Semiautomático Proposto } \\
\hline Imagem & Intercepto Linear Médio $(\boldsymbol{\mu m})$ & Imagem & Intercepto Linear Médio $(\boldsymbol{\mu m})$ \\
\hline 1 & 12,24 & 2 & 13,51 \\
\hline 4 & 12,46 & 3 & 13,17 \\
\hline 6 & 13,13 & 5 & 13,58 \\
\hline 8 & 12,29 & 9 & 13,81 \\
\hline 10 & 12,72 & 11 & 13,49 \\
\hline 12 & 12,71 & 13 & 14,19 \\
\hline 14 & 12,73 & 15 & 13,87 \\
\hline 16 & 12,80 & 18 & 13,18 \\
\hline 20 & 13,91 & 19 & 15,05 \\
\hline
\end{tabular}

Alguns parâmetros estatísticos das medidas também foram calculados. Os resultados estão apresentados na Tabela 3.

Tabela 3. Parâmetros estáticos calculados referentes aos métodos semiautomáticos padronizado e proposto.

\begin{tabular}{cccccc}
\hline Metodologia & $\begin{array}{c}\text { Número de } \\
\text { campos } \\
\text { avaliados }\end{array}$ & $\begin{array}{c}\text { Média } \\
\text { Amostral } \\
(\boldsymbol{\mu m})\end{array}$ & $\begin{array}{c}\text { Desvio } \\
\text { Padrão }\end{array}$ & $\begin{array}{c}\text { Limites de } \\
\text { confiança de } \\
\mathbf{9 5 \%}\end{array}$ & $\begin{array}{c}\text { Precisão } \\
\text { relativa (\%) }\end{array}$ \\
\hline $\begin{array}{c}\text { Método } \\
\text { Normatizado }\end{array}$ & 9 & 12,78 & 0,51 & $12,78 \pm 0,39$ & 3,05 \\
\hline $\begin{array}{c}\text { Método } \\
\text { Proposto }\end{array}$ & 9 & 13,76 & 0,58 & $13,76 \pm 0,45$ & 3,27 \\
\hline
\end{tabular}

De acordo com a norma ASTM E112, caso a precisão relativa calculada seja menor que $10 \%$, campos adicionais não precisam ser avaliados. Por essa razão, outras imagens não foram analisadas no presente trabalho.

Percebe-se que a metodologia semiautomática proposta tende a apresentar a média do intercepto linear superior, comparado ao mesmo parâmetro obtido pela aplicação do procedimento semiautomático padronizado pela ASTM. Esse fato pode ter ocorrido devido às medianas horizontais e medianas verticais dos grãos apresentarem, aparentemente, os maiores valores de intercepto linear, razão pela qual superestima os resultados.

Apesar dos interceptos lineares obtidos nos métodos semiautomáticos avaliados serem diferentes, o tamanho de grão ASTM foi calculado para as duas metodologias. Os resultados são apresentados na Tabela 4.

Tabela 4. Tamanho de grão ASTM encontrado para as metodologias semiautomáticas padronizada e proposta.

\begin{tabular}{cc}
\hline Metodologia & Tamanho de Grão ASTM (G) \\
\hline Método semiautomático padronizado & 9,29 \\
\hline Método semiautomático proposto & 9,08 \\
\hline
\end{tabular}


Nota-se que a diferença absoluta entre os valores do tamanho de grão ASTM é relativamente pequena. Desta maneira, a aplicação do método proposto torna-se uma alternativa viável para o cálculo do tamanho médio de grão em amostras metálicas policristalinas monofásicas. Além disso, como esse método utiliza medidas individuais dos grãos, ele pode ser utilizado para analisar a distribuição de frequência do tamanho de grão na estrutura de um material.

\subsection{Métodos Automáticos}

Partindo da hipótese de uma segmentação manual ideal das imagens, o tamanho médio dos grãos foi novamente estimado, mas de maneira automática. Os resultados da aplicação do método automático das áreas individuais dos grãos, normatizado pela ASTM E1382, e das duas metodologias automáticas propostas, são apresentados na Tabela 5.

Tabela 5. Valor médio por imagem dos parâmetros calculados pelas metodologias automáticas.

\begin{tabular}{cccc}
\hline \multirow{2}{*}{ Imagem } & $\begin{array}{c}\text { Método Automático } \\
\text { Normatizado }\end{array}$ & $\begin{array}{c}\text { Método Automático } \\
\text { Proposto 1 }\end{array}$ & $\begin{array}{c}\text { Método Automático } \\
\text { Proposto 2 }\end{array}$ \\
\cline { 2 - 4 } & $\begin{array}{c}\text { Área Média dos Grãos } \\
\left(\boldsymbol{\mu m ^ { 2 } )}\right.\end{array}$ & $\begin{array}{c}\text { Diâmetro Equivalente } \\
\text { Médio }(\boldsymbol{\mu m})\end{array}$ & $\begin{array}{c}\text { Média entre os principais } \\
\text { eixos da elipse }(\boldsymbol{\mu m})\end{array}$ \\
\hline 1 & 112,82 & 11,13 & 13,23 \\
\hline 4 & 95,70 & 10,39 & 11,98 \\
\hline 6 & 96,95 & 10,33 & 11,91 \\
\hline 8 & 91,66 & 9,94 & 11,66 \\
\hline 10 & 92,25 & 10,07 & 11,78 \\
\hline 12 & 88,30 & 9,65 & 11,54 \\
\hline 14 & 82,59 & 9,51 & 11,17 \\
\hline 16 & 83,52 & 9,60 & 11,38 \\
\hline 20 & 94,63 & 10,13 & 11,86 \\
\hline
\end{tabular}

Alguns parâmetros estatísticos das medidas também foram calculados. Os resultados encontrados são apresentados na Tabela 6.

Tabela 6. Parâmetros estáticos calculados referentes aos métodos automáticos aplicados.

\begin{tabular}{cccccc}
\hline Metodologia & $\begin{array}{c}\text { Número de } \\
\text { campos } \\
\text { avaliados }\end{array}$ & $\begin{array}{c}\text { Média } \\
\text { Amostral }\end{array}$ & $\begin{array}{c}\text { Desvio } \\
\text { Padrão }\end{array}$ & $\begin{array}{c}\text { Limites de } \\
\text { confiança de } \\
\mathbf{9 5 \%}\end{array}$ & $\begin{array}{c}\text { Precisão } \\
\text { relativa (\%) }\end{array}$ \\
\hline $\begin{array}{c}\text { Método } \\
\text { Normatizado }\end{array}$ & 9 & $93,16 \mu \mathrm{m}^{2}$ & 8,95 & $93,16 \pm 6,88$ & 7,38 \\
\hline $\begin{array}{c}\text { Método } \\
\text { Proposto 1 }\end{array}$ & 9 & $10,08 \mu \mathrm{m}$ & 0,50 & $10,08 \pm 0,39$ & 3,83 \\
\hline $\begin{array}{c}\text { Método } \\
\text { Proposto 2 }\end{array}$ & 9 & $11,84 \mu \mathrm{m}$ & 0,59 & $11,84 \pm 0,45$ & 3,80 \\
\hline
\end{tabular}

Os valores obtidos por ambos os métodos automáticos propostos foram considerados como sendo de mesma natureza e conceito que o intercepto linear dos grãos. Desse modo, o tamanho de grão G ASTM foi calculado para as três metodologias automáticas aplicadas, utilizando-se para tanto as devidas equações fornecidas pela norma ASTM E1382. Os resultados são apresentados na Tabela 7.

Tabela 7. Tamanho de grão ASTM encontrado para as metodologias automáticas aplicadas.

\begin{tabular}{cc}
\hline Metodologia & Tamanho de Grão ASTM (G) \\
\hline Área Média dos Grãos & 10,44 \\
\hline Diâmetro Equivalente & 9,98 \\
\hline Média entre os principais eixos da elipse & 9,51 \\
\hline
\end{tabular}


Adotando o valor do tamanho de grão ASTM obtido pelo método automático normatizado como referência, notou-se que as metodologias automáticas propostas superestimam os resultados. Em outras palavras, os grãos são considerados maiores do que seu tamanho medido pelo método padrão.

Entretanto, percebe-se que a diferença absoluta entre os tamanhos de grão G ASTM obtidos pelos procedimentos propostos e o mesmo parâmetro obtido pelo método normatizado, novamente, é relativamente pequena. Portanto, a aplicação dos métodos automáticos propostos torna-se uma alternativa viável para o cálculo do tamanho médio de grão em amostras metálicas policristalinas monofásicas.

O ataque químico é uma etapa crítica da avaliação dos grãos por métodos automáticos, visto que os limites dos cristais após esse processo devem se apresentar perfeitamente definidos. Um ataque químico por um período relativamente pequeno ou demasiado, bem como o uso de um reativo inadequado, irá exercer forte influência na definição dos contornos. Desse modo, o desenvolvimento de técnicas de processamento de imagens para completar contornos de grãos mal definidos são extremamente relevantes.

Nota-se que, ao comparamos os resultados dos dois métodos padronizados aplicados, semiautomático e automático, a diferença encontrada é de mais de 1 (uma) unidade G. Isso pode ter ocorrido devido à metodologia semiautomática avaliar um numero muito menor de grãos comparado ao procedimento automático. Não obstante, podem ter ocorrido erros durante a segmentação manual das imagens, visto que foi uma etapa muito tediosa do trabalho.

Os resultados para o parâmetro que determina morfologia dos grãos são apresentados na Tabela 8.

Tabela 8. Razão média por imagem entre o maior e menor eixo da elipse que melhor se ajusta a cada grão.

\begin{tabular}{cc}
\hline Imagem & $\begin{array}{c}\text { Razão Média entre os dois principais eixos das } \\
\text { elipses que melhor se ajustam aos grãos }\end{array}$ \\
\hline 1 & 2,15 \\
\hline 4 & 1,88 \\
\hline 6 & 1,55 \\
\hline 8 & 1,96 \\
\hline 10 & 1,18 \\
\hline 12 & 1,58 \\
\hline 14 & 1,63 \\
\hline 16 & 1,39 \\
\hline 20 & 1,91 \\
\hline
\end{tabular}

Ao dividir o comprimento do maior eixo de uma elipse pelo comprimento do seu menor eixo é esperado que o valor dessa razão se aproxime de uma unidade, caso a região se assemelhe a uma circunferência. Portanto, pela análise dos resultados, 0 material estudado apresenta grãos alongados, visto que a média da razão entre os eixos foi de 1,69.

O tempo para calcular o tamanho de grão G ASTM pelas metodologias automáticas utilizadas no trabalho, após as imagens terem sido segmentadas, apresentou-se muito inferior ao tempo necessário para encontrar o referido parâmetro utilizando os métodos semiautomáticos. Enquanto as análises automáticas foram realizadas em menos de 1 (um) minuto, as metodologias semiautomáticas consumiram aproximadamente $2 \mathrm{~h}$. 


\section{CONCLUSÃO}

A metodologia semiautomática proposta tende a apresentar a média do intercepto linear superior à obtida pelo método padronizado dos interceptos.

Ao considerar o tamanho de grão G ASTM, o método semiautomático proposto torna-se uma alternativa viável para o cálculo do tamanho médio de grão.

Deve-se desenvolver técnicas de processamento de imagens para facilitar a segmentação de modo automático, visto que a segmentação manual é trabalhosa e tediosa, o que pode levar a erros durante o processo.

O tempo para calcular o tamanho de grão G ASTM pelas metodologias automáticas é muito inferior ao utilizado para calcular o mesmo parâmetro pelos métodos semiautomáticos.

As metodologias automáticas propostas são alternativas viáveis para o cálculo do tamanho médio de grão.

O parâmetro que determina a morfologia dos grãos é um parâmetro viável para estimar a forma dos grãos.

Os grãos do material utilizado no presente trabalho encontram-se ligeiramente alongados.

\section{Agradecimentos}

Os autores gostariam de agradecer ao Conselho Nacional de Pesquisa e Desenvolvimento - CNPq pelo apoio financeiro a pesquisa realizada, assim como ao Laboratório de Tratamentos Térmicos e Microscopia Óptica (LTM) do DEMET-EMUFOP pela infraestrutura disponibilizada para a realização do presente trabalho.

\section{REFERÊNCIAS}

1 Shou, W. B., Yi, D. Q., Liu, H. Q., Tang, F. H. Shen, Wang, B. Effect of grain size on the fatigue crack growth behavior of 2524-T3 aluminum alloy. Archives of Civil and Mechanical Engineering. 2016; 16:304-312.

2 Zhang, Y., Dai, X., Jia, D. Li, H. Wang, Y. The effects of grain size on yielding, strain hardening, and mechanical twinning in Fe-18Mn-1,5Al twinning-induced plasticity steel. Materials Science and Engineering: A. 2016; 652:212-220.

3 Ning, Z. L., Liu, H. H., Cao, F. Y., Wang, S. T., Sun, J. F., Qian, M. The effect of grain size on the tensile and creep properties of $\mathrm{Mg}-2.6 \mathrm{Nd}-0.35 \mathrm{Zn}-\mathrm{xZr}$ alloys at $250^{\circ} \mathrm{C}$. Materials Science and Engineering: A. 2013; 560:163-169.

4 Ahadi, A., Sun, Q. Grain Size dependence of fracture toughness and crack-growth resistance of superelastic NiTi. Scripta Materialia. 2016;113:171-175.

$5 \mathrm{Li}, \mathrm{X}$., Ma, X., Subramanian, S. V. Shang, C., Misra, R. D. K. Influence of prior austenite grain size on martensite-austenite constituent and toughness in the heat affected zone of $700 \mathrm{MPa}$ high strenght lineppipe steel. Materials Science and Engineering: A. 2016; 616:141-147.

6 American Society For Testing And Materials. E112 - 96: Standard Test Methods For Determining Average Grain Size. 1996.

7 American Society For Testing And Materials. E1382 - 97: Standard Test Methods For Determining Average Grain Size Using Semiautomatic And Automatic Image Analysis. 1997.

8 Peregrina-Barreto H, Terol-Villalobos IR, Rangel-Magdaleno JJ, Herrera-Navarro AM, Morales-Hernández LA, Manríquez-Guerrero F. Automatic grain size determination in microstructures using image processing. Measurement. 2013; 46: 249-258.

9 Latala Z, Wojnar L. Computer-aided versus manual grain size assessment in a single phase material. Materials Characterization. 2001, 46: 227-233. 